\title{
Repeated hepatic resections and radio-frequency ablations may improve the survival of adult undifferentiated embryonal sarcoma of the liver: report of two cases
}

\author{
Toshiro Masuda ${ }^{1}$, Toru Beppu ${ }^{1,2}$, Koichi Doi ${ }^{1}$, Tatsunori Miyata ${ }^{1}$, Shigeki Nakagawa ${ }^{1}$, Hirohisa Okabe ${ }^{1}$, \\ Hiromitsu Hayashi', Takatoshi Ishiko', Ken-ichi lyama ${ }^{3}$ and Hideo Baba ${ }^{1 *}$
}

\begin{abstract}
Undifferentiated embryonal sarcoma of the liver (UESL) in adults, especially over 30 years old, is quite rare. We report two adult UESL patients that one of them survived 62 months and one is now surviving more than 65 months treated with repeated hepatic resections and radio-frequency ablations. Although UESL is an entirely unusual and aggressive tumor, multidisciplinary treatments including repeated hepatic resections and radiofrequency ablations may provide a longer survival.
\end{abstract}

Keywords: Undifferentiated embryonal sarcoma; Hepatic resection; Radio-frequency ablation

\section{Background}

Undifferentiated embryonal sarcoma of the liver (UESL) is a rare malignant tumor commonly observed in children [1]. UESL in adults, especially more than 30 years old, is entirely uncommon [2,3]. Because of its infrequency, treatment strategy of UESL in adult is not well established [3, 4]. We have reported short-term outcomes of two adult patients of UESL treated with hepatic resection separately in Japanese literatures $[5,6]$. In one of those reports, we emphasized that the patient was successfully treated with a major hepatic resection even for the huge tumor with congestion of three hepatic veins and inferior vena cava [5]. The other reported the pathological feature of the case of UESL [6]. We herein report the long-term outcomes of two cases of adult UESL treated with multiple courses of hepatic resections and radio-frequency ablations (RFAs) for the repeated recurrent diseases.

\footnotetext{
* Correspondence: hdobaba@kumamoto-u.ac.jp

'Department of Gastroenterological Surgery, Graduate School of Medical Sciences, Kumamoto University, 1-1-1, Honjo, Chuo-ku, Kumamoto 860-0811, Japan

Full list of author information is available at the end of the article
}

\section{Case presentation}

Case 1

A 52-year-old female was admitted to the hospital to treat a huge liver tumor with complaints of dyspnea, severe abdominal distension, and lower-extremity edema. Hepatitis B virus surface antigen (HBs-Ag) and hepatitis $\mathrm{C}$ virus antibody ( $\mathrm{HCV}-\mathrm{Ab})$ were negative. The serum level of DUPAN-II was $810 \mathrm{U} / \mathrm{ml}$ and that of CA125 was $157 \mathrm{IU} / \mathrm{ml}$, and alpha-fetoprotein (AFP), protein induced by vitamin $\mathrm{K}$ absence (PIVKA-II), carcinoembryonic antigen (CEA), and carbohydrate antigen 19-9 (CA19-9) were in the normal range. Computed tomography (CT) showed a huge low-density tumor with a clear margin, $23 \mathrm{~cm}$ in diameter, and showed little enhancement after administration of contrast medium (Fig. 1a). Magnetic resonance (MR) imaging demonstrated the multicystic tumor to be hypointense on T1-weighted images (Fig. 1b) and hyperintense on T2-weighted images (Fig. 1c). A right tri-sectionectomy as the first operation was performed safely and successfully, even though the tumor entirely compressed the inferior vena cava and the root of three hepatic veins. Operation time was $13 \mathrm{~h}$ and intraoperative bleeding was $2400 \mathrm{~g}$. Resected specimen showed a heterogenic tumor sized $23 \times 22 \times 11 \mathrm{~cm}$ (Fig. 1d). Histologically, spindled, oval, or stellate tumor 

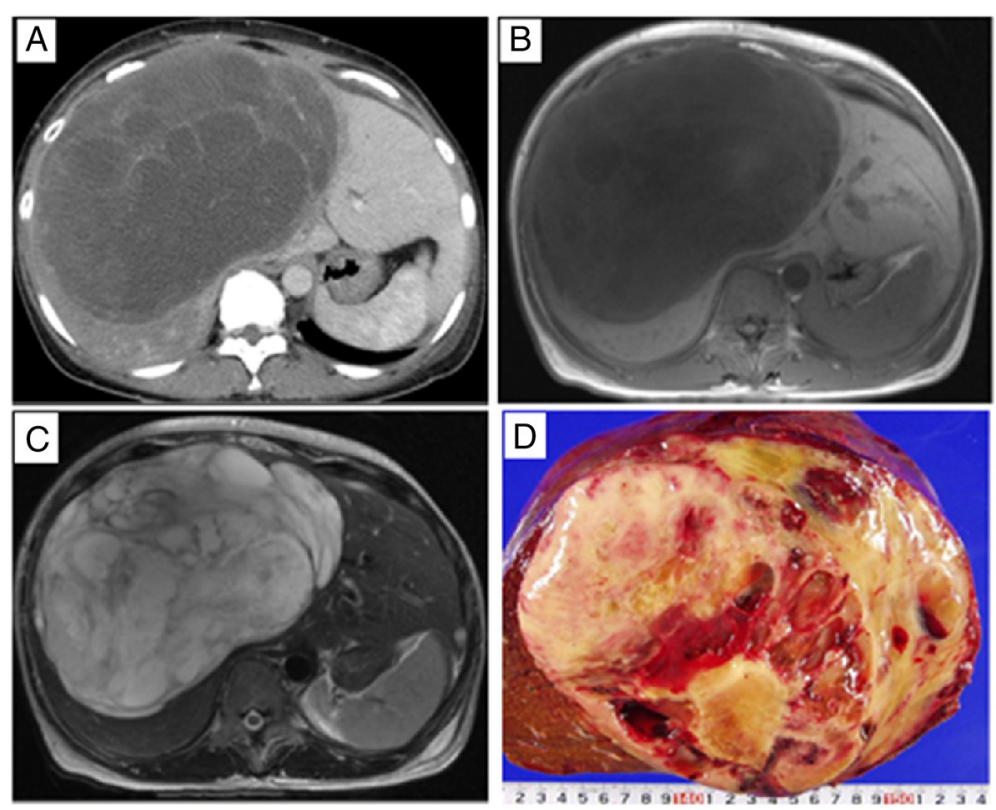

Fig. 1 Computed tomography showed a huge low-density tumor sized $17 \mathrm{~cm}$ in diameter that showed little enhancement (a). Magnetic resonance imaging showed a multicystic tumor to be hypointense on T1-weighted images (b) and hyperintense on T2-weighted images (c). Resected specimen showed a heterogenic tumor, $23 \times 22 \times 11 \mathrm{~cm}$ in diameter (d)

cells were distributed in myxoid or fibrous stroma. Multiple varying-sized cytoplasmic eosinophilic globules were seen (Fig. 2a, b). Immunohistologically, tumor cells were positive for vimentin (Fig. 2c), alpha 1-antitrypsin (Fig. 2d), and alpha 1-antichymotrypsin (Fig. 2e), and partially positive for alpha-smooth muscle actin (SMA) and CD68/kp-1. S-100, calponin, cytokeratin, factor VIII, CD34, and AFP were negative in tumor cells. The MIB-1 index was $20 \%$ (Fig. 2f). Finally, the tumor was histologically diagnosed as a UESL, and the liver parenchyma
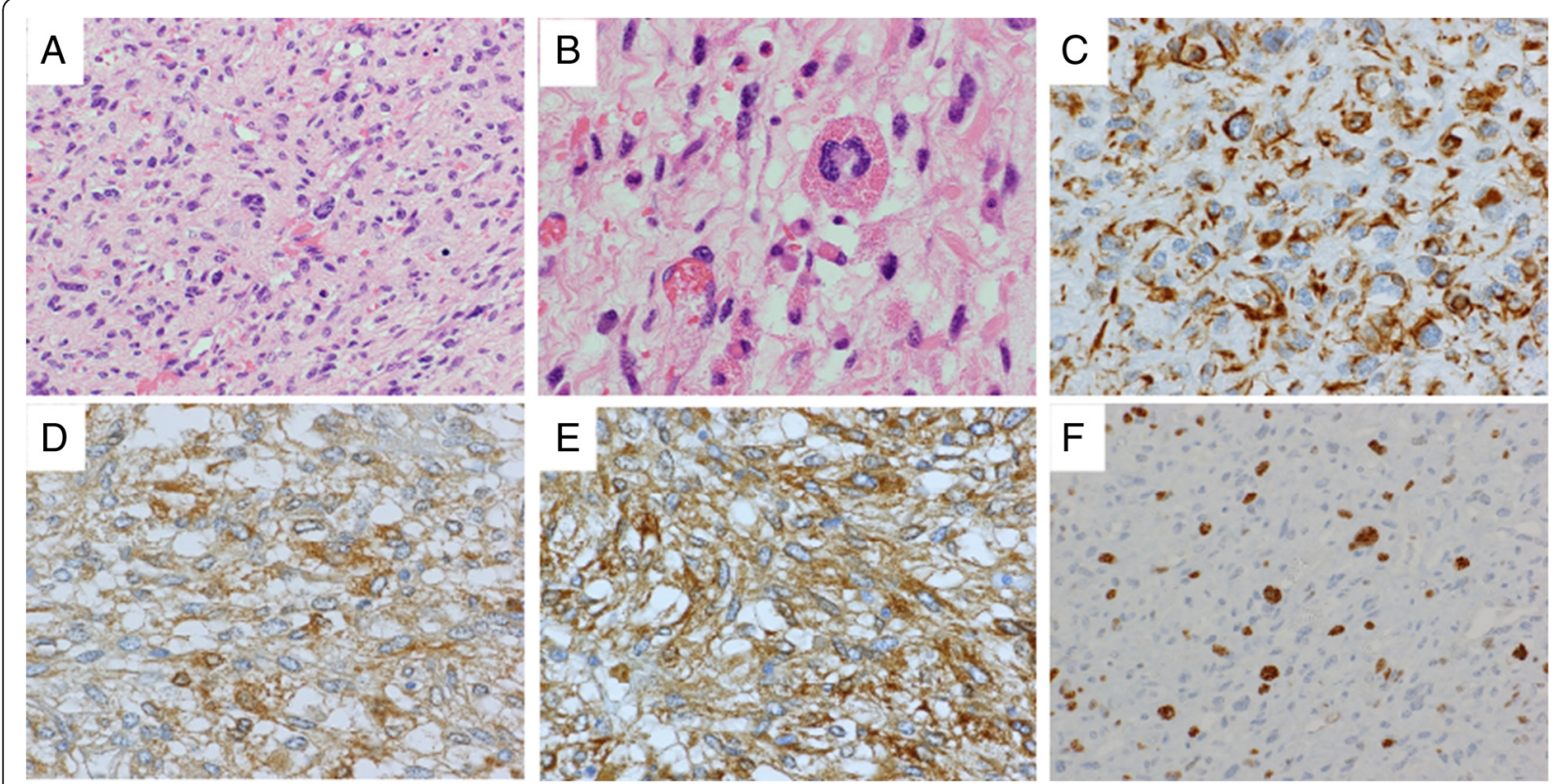

Fig. 2 Histological features of HE staining $(\times 200, \mathbf{a} ; \times 400$, b) showed spindled, oval, or stellate tumor cells distributed in myxoid or fibrous stroma. Multiple varying-sized cytoplasmic eosinophilic globules were seen. Tumor cells were positive for vimentin $(\times 400, \mathbf{c})$, alpha 1-antitrypsin $(\times 400$, d), and alpha 1-antichymotrypsin ( $\times 400, \mathbf{e})$. The MIB-1 index was $20 \%(\times 200, \mathbf{f})$ 
was normal liver. Twelve and 19 months after the first operation, for the sequential recurrent diseases, a left caudate lobectomy and a partial hepatectomy of segment 3 were performed as the second and the third surgery, respectively. Twenty months after the first operation, twice transarterial chemoembolizations (TACEs) with CDDP $50 \mathrm{mg}$ + lipiodol $2.5 \mathrm{ml}$, epirubicin $30 \mathrm{mg}$, and gelatin sponge were performed. Twenty-five months after the first operation, a radio-frequency ablation (RFA) was performed (pre, Fig. 3a, c; post, Fig. 3b, d). Thirtyfive, 42, and 47 months after the first operation, two times of partial hepatic resections and a hepatectomy in combination with RFA (pre, Fig. 3e; post, Fig. 3f) were additionally performed. Because of bone metastases and tumor thrombosis in azygos vein, she unfortunately died 62 months after the initial hepatectomy.

\section{Case 2}

A 53-year-old female was admitted to our hospital with a huge liver tumor with symptoms of epigastralgia and back pain. Her HBs-Ag and HCV-Ab were negative. Serum level of PIVKA-II was elevated to 10,369 mAU/ $\mathrm{ml}$, and AFP, CEA, and CA19-9 were in the normal range. CT showed a huge low-density tumor sized $18 \times$ $14 \mathrm{~cm}$ that showed mild enhancement after administration of contrast medium (Fig. 4a). MR imaging demonstrated the heterogeneous tumor to be hypointense on T1-weighted images (Fig. 4b) and hyperintense on T2weighted images (Fig. 4c). Some satellite lesions suspected as cavernous hemangiomas were identified in the bilateral lobe of the liver. The first extended left hepatectomy was performed. Operation time was $459 \mathrm{~min}$ and intraoperative bleeding was $877 \mathrm{~g}$. Resected specimen revealed a tumor with multiple components, sized $22 \times 19 \times$ $14 \mathrm{~cm}$ (Fig. 4d). Histologically, spindled, oval, or stellate tumor cells were distributed in myxoid or fibrous stroma. Nuclear pleomorphism and hyperchromasia with frequent multinucleated or bizarre giant cells were apparent. Multiple varying-sized cytoplasmic eosinophilic globules were seen (Fig. 5a, b). The tumor cells were positive for vimentin (Fig. 5c), alpha 1-antitrypsin (Fig. 5d), alpha 1antichymotrypsin (Fig. 5e), and desmin, and partially positive for CD34 and alpha-SMA. The MIB-1 index was $30 \%$ (Fig. 5f). Hepatocyte specific antigen (HSA) and cytokeratin were negative in the tumor. The tumor was histologically diagnosed as a UESL in the normal liver.
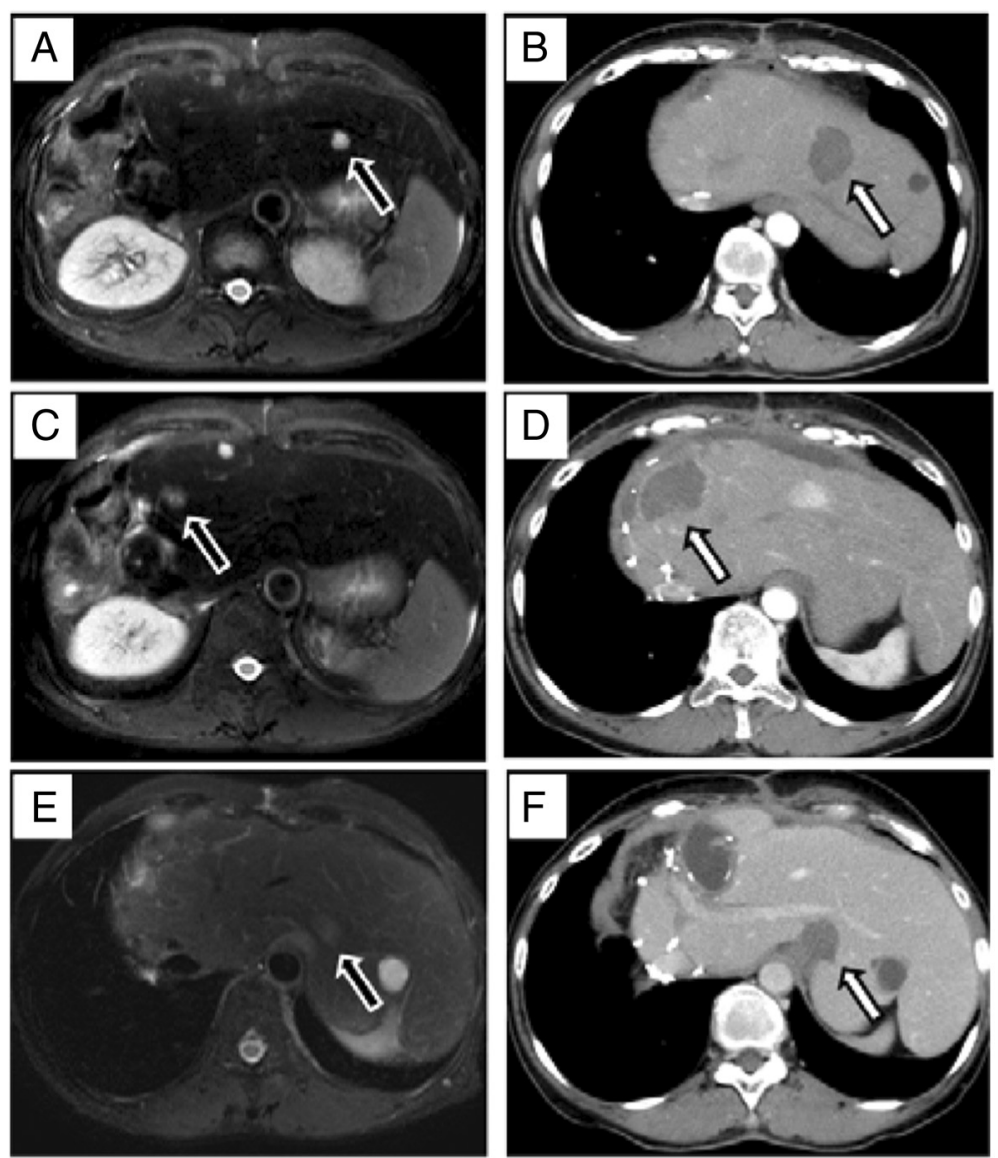

Fig. 3 Three recurred tumors (arrows; a, c, e) were successfully treated with radio-frequency ablations (arrows; b, d, f), respectively 

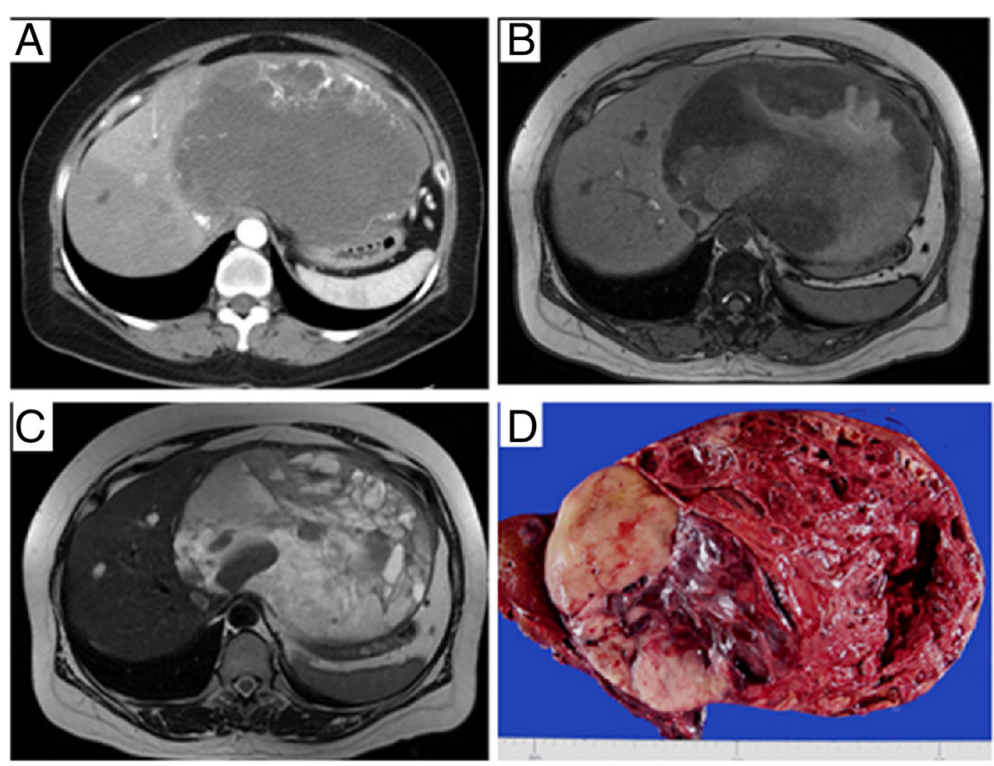

Fig. 4 Computed tomography showed a huge low-density tumor sized $18 \times 14 \mathrm{~cm}$ that showed mild enhancement (a). Magnetic resonance imaging showed the tumor to be hypointense on T1-weighted images $(\mathbf{b})$ and mixed hyperintense on T2-weighted images (c). Resected specimen revealed a tumor with multiple components sized $22 \times 19 \times 14 \mathrm{~cm}$ (d)

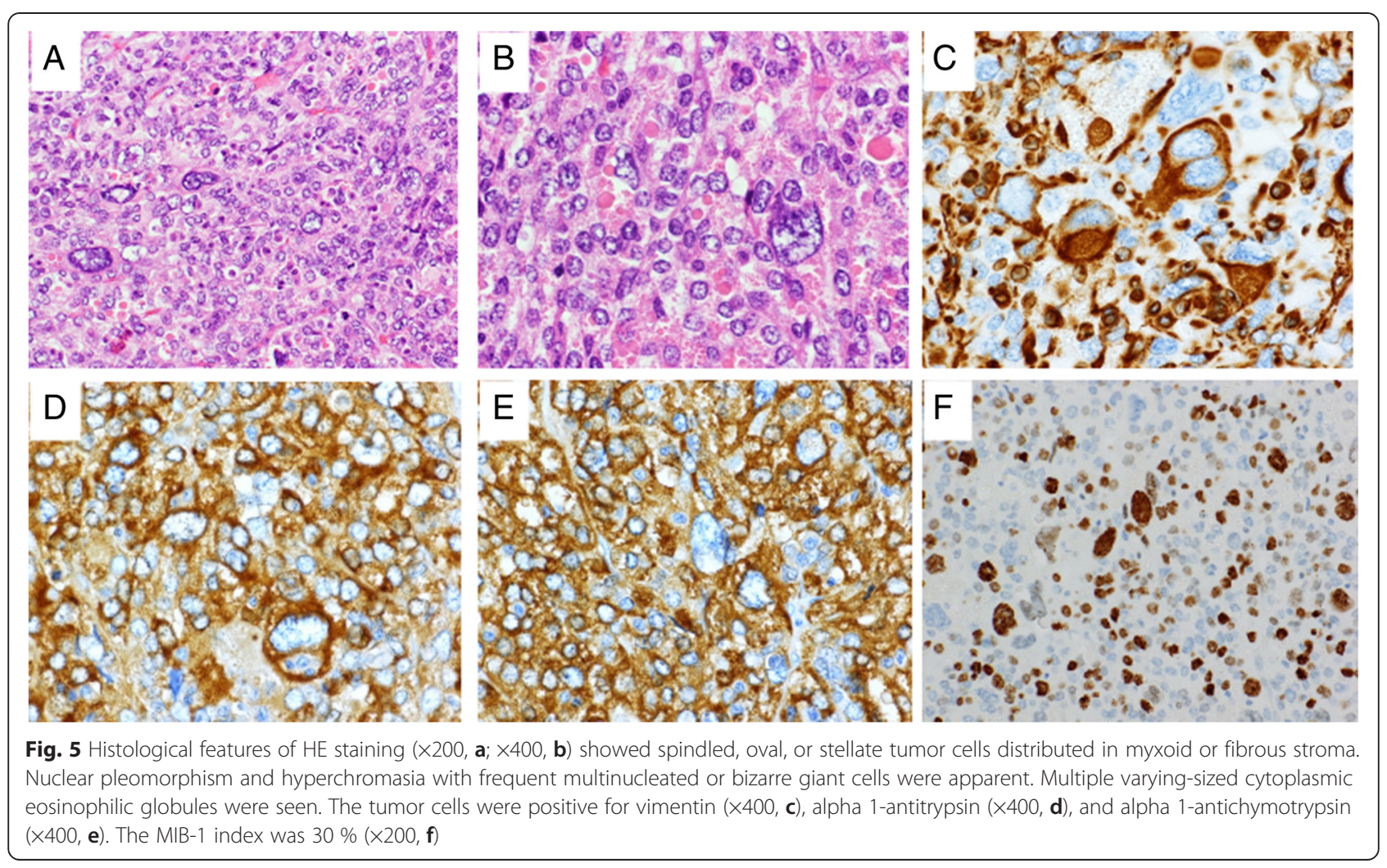



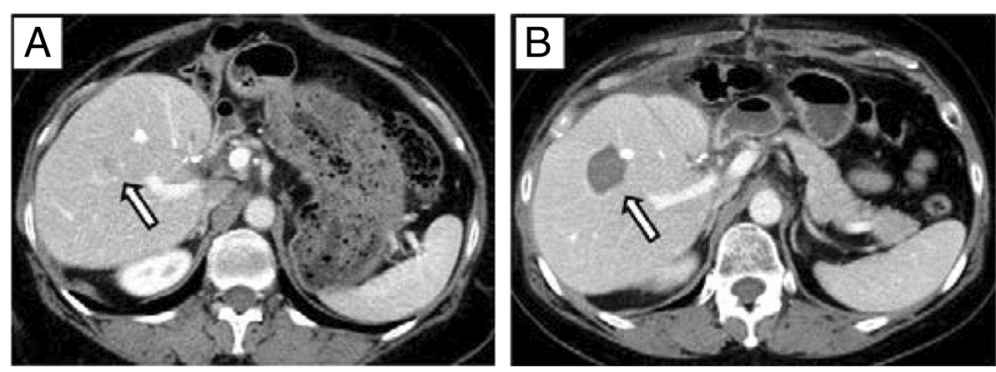

Fig. 6 The recurred tumor (arrow, a) was successfully treated with radio-frequency ablation (arrow, b).

Three months after the first operation, a TACE (CDDP $80 \mathrm{mg}+$ lipiodol $4 \mathrm{ml}, 5$-FU $1000 \mathrm{mg}$, and gelatin sponge) was performed. Four and 14 months after the first operation, a partial hepatic resection of segments 6 and 7 and a partial hepatic resection of segment 8 in combination with RFA (pre, Fig. 6a; post, Fig. 6b) were also performed, respectively. She is now alive without any recurrent diseases for more than 65 months from the initial hepatic resection.

\section{Conclusions}

UESL in adult is extremely rare and the prognosis of UESL patients is very poor $[3,4,7]$. Although the treatment strategy of adult UESL is not well established, if possible, liver resection and adjuvant chemotherapy are recommended [7].

Two cases of adult UESL patients were occasionally admitted to our hospital in the same period. Instead of the huge size of the tumors, both patients were successfully treated with the initial hepatic resections. The first patient survived 62 months with receiving a total six times of hepatic resection, twice RFAs, and two times of TACEs. The second patient received three times of hepatic resection and a TACE and RFA and is still alive more than 65 months from the initial treatment. Both patients received no adjuvant chemotherapy or radiotherapy.

UESL has been reported to be chemotherapy-sensitive or is highly sensitive to TACE $[3,7]$. However, the reported regimens of chemotherapy for adult UESL were heterogeneous [7]. As systemic chemotherapy, sarcomadirected one such as vincristine, actinomycin, ifosfamide, doxorubicin, carboplatin, or etoposide was often selected for metastatic UESL [7]. In the current patients, TACE was selected to treat the intrahepatic multiple recurrences of the UESL. Sarcoma-directed chemo-drugs were not established as the regimens of TACE, so a combination of CDDP, epirubicin, and 5-FU was used [8]. In the current two patients, TACE was not so effective; thereafter, repeated hepatic resections or RFAs were mainly selected.

Noguchi et al. reported a long-term survival case of adult UESL treated with hepatic resection, adjuvant chemotherapy, and additional radiotherapy [9]. They also reviewed the reported long-term survival cases of adult UESL and discussed that complete resection is important for ensuring long-term survival. In the treatment strategy of liver tumors, the effectiveness of RFA as well as surgical resection is widely reviewed [10]. To the best of our knowledge, there are no English reports of adult UESL treated with RFA. In the current cases, four tumors treated with RFA showed no recurrences at the therapeutic sites for mean observation period of 35 months. RFA can be one of the effective modalities to treat UESL, especially in cases with multiple small intrahepatic recurrences. Repeated hepatectomies and RFAs for the recurrent diseases may influence such long survivals of the current adult UESL patients.

In conclusion, although adult UESL is a rare and aggressive malignancy, repeated hepatic resections and RFAs for the recurrent diseases may provide a longer survival.

\section{Consent}

Written informed consents were obtained from patients and their family for publication of this case report and any accompanying images. Copies of the written consents are available for review by the Editor-in-Chief of this journal.

\section{Abbreviations}

AFP: alpha-fetoprotein; CA19-9: carbohydrate antigen 19-9;

CEA: carcinoembryonic antigen; CT: computed tomography; HBs-Ag: hepatitis B virus surface antigen; HCV-Ab: hepatitis C virus antibody; MR: magnetic resonance; PIVKA-II: protein induced by vitamin $\mathrm{K}$ absence; RFA: radio-frequency ablation; TACE: transarterial chemoembolization; UESL: undifferentiated embryonal sarcoma of the liver.

\section{Competing interests}

The authors declare that they have no competing interests.

\section{Authors' contributions}

$\mathrm{TOM}, \mathrm{TB}$, and $\mathrm{HB}$ participated in the study design and drafted the manuscript. KD, TaM, SN, HO, HH, and TI participated in the clinical treatments. $\mathrm{KI}$ carried out the pathological studies. All authors read and approved the final manuscript.

\section{Author details}

${ }^{1}$ Department of Gastroenterological Surgery, Graduate School of Medical Sciences, Kumamoto University, 1-1-1, Honjo, Chuo-ku, Kumamoto 860-0811, Japan. ${ }^{2}$ Department of Multidisciplinary Treatment for Gastroenterological Cancer, Kumamoto University Hospital, Kumamoto, Japan. ${ }^{3}$ Department of Surgical Pathology, Kumamoto University Hospital, Kumamoto, Japan. 
Received: 26 December 2014 Accepted: 10 June 2015

Published online: 27 June 2015

\section{References}

1. Stocker JT, Ishak KG. Undifferentiated (embryonal) sarcoma of the liver: report of 31 cases. Cancer. 1978;42(1):336-48.

2. Mistry RC, Deshpande RK, Chinoy R, Sampat M, Desai PB. Undifferentiated embryonal sarcoma of the liver in childhood. Indian J Cancer.

1995;32(4):175-8.

3. Li XW, Gong SJ, Song WH, Zhu JJ, Pan CH, Wu MC, et al. Undifferentiated liver embryonal sarcoma in adults: a report of four cases and literature review. World J Gastroenterol. 2010;16(37):4725-32.

4. Lightfoot N, Nikfarjam M. Embryonal sarcoma of the liver in an adult patient. Case Rep Surg. 2012;2012:382723.

5. Hirata T, Beppu T, Isiko T, Sugiyama S, Takamori H, Kanemitu K, et al. A successfully resected case of undifferentiated sarcoma of the liver with congestion of hepatic vein and inferior vena cava. Jpn J Gastroenterol Surg (in Japanese). 2007;40(5):623-8.

6. Asato T, Honda Y, Ishihara S, Masuda T, Hirashima K, Beppu T, et al. An adult case of undifferentiated (embryonal) sarcoma of the liver. Jpn J Diagn Pathol (in Japanese). 2010;27(4):280-4.

7. Lenze F, Birkfellner T, Lenz P, Hussein K, Langer F, Kreipe $H$, et al. Undifferentiated embryonal sarcoma of the liver in adults. Cancer. 2008;112(10):2274-82.

8. Liapi E, Geschwind JF. Chemoembolization for primary and metastatic liver cancer. Cancer J. 2010;16(2):156-62.

9. Noguchi K, Yokoo H, Nakanishi K, Kakisaka T, Tsuruga Y, Kamachi H, et al. A long-term survival case of adult undifferentiated embryonal sarcoma of liver. World J Surg Oncol. 2012;10:65.

10. Sutherland LM, Williams JA, Padbury RT, Gotley DC, Stokes B, Maddern GJ. Radiofrequency ablation of liver tumors: a systematic review. Arch Surg. 2006;141(2):181-90.

\section{Submit your manuscript to a SpringerOpen ${ }^{\circ}$ journal and benefit from:}

- Convenient online submission

- Rigorous peer review

- Immediate publication on acceptance

- Open access: articles freely available online

- High visibility within the field

- Retaining the copyright to your article

Submit your next manuscript at $>$ springeropen.com 